\title{
INDÚSTRIA DE PETRÓlEO E GÁS: ANÁlISE COMPARATIVA DA LEGISLAÇÃO AMBIENTAL DOS EUA E BRASIL
}

\section{PETROLEUM AND GAS INDUSTRY: A COMPARATIVE ANALISYS OF USA AND BRAZIL'S ENVIRONMENTAL LEGISLATION}

\section{J. F. M. MOREIRA ${ }^{1, *}$, A. L. D’ALMEIDA ${ }^{1}$}

${ }^{1}$ Fluminense Federal University, School of Engineering, Niterói, Rio de Janeiro, Brazil

${ }^{*}$ Fluminense Federal University, School of Engineering, Niterói, Rio de Janeiro, Brazil, Phone: +5521974478086

e-mail address: julianafisher@id.uff.br (J.F.M. Moreira).

\section{A R T I C L E I N F O}

Article history:

Received 2018-10-16

Accepted 2018-12-21

Available online 2019-04-25

\section{palavras-chave \\ Legislação ambiental \\ Brasil}

Estados Unidos da América

keywords

Environmental legislation

Brazil

United States of America
A B S T R A C T

Any operation related to petroleum is subject to environmental impacts, due to the fact that this fossil fuel is highly contaminating and flammable. After a large-scale incident, in addition to the fines provided by law, legal instruments and international conventions are created to protect the environment and the living beings that are part of it. Through instruments, such as laws and regulations, the State plays a central role in environmental preservation and operational safety of activities involving oil. The work was aimed at scrutinizing the activities of the agencies involved in environmental protection and the environmental and safety legislation of Brazil and United States of America (USA). These countries were chosen because of their references in preservation of the environment and operational safety, besides being important oil producers.

\section{RES UM O/RES UMEN}

Qualquer operação ligada a petróleo está sujeita a impactos ambientais, devido ao fato desse combustível fóssil ser altamente contaminante e inflamável. Em um incidente de grande escala, além das multas previstas por lei, instrumentos legais e convenções internacionais são criados a fim de resguardar o meio ambiente e os seres vivos que o integram. Por meios de tais instrumentos, como leis e regulamentos, o Estado tem um papel central na preservação ambiental e segurança operacional das atividades que englobam petróleo. Buscou-se esmiuçar a atuação dos órgãos envolvidos na proteção do meio ambiente e as legislações ambientais e de segurança do Brasil e Estados Unidos da América (EUA). Esses países foram escolhidos por causa de suas referências em preservação do meio ambiente e segurança operacional, além de serem importantes produtores de petróleo. 


\section{INTRODUÇÃO}

Muitos acidentes envolvendo petróleo ocorreram e ocorrerão, entre os mais conhecidos, o incêndio na Vila Socó e o blowout na plataforma Deepwater Horizon. Esses episódios justificam a diligência para regulação e restrição ambiental de atividades que abrangem esse combustível.

Esses acontecimentos frequentes revelam seus impactos ambientais. Os governantes, preocupados com proteção ambiental, instituem leis, regulamentos e penalidades, cada vez mais rigorosos. É consenso que a indústria precisa ser rigorosamente fiscalizada, por razões econômicas, políticas e principalmente ambientais (GAO, 1998).

Esse artigo objetiva realizar comparações dos arcabouços regulatórios do Brasil e EUA, discorrendo sobre as entidades controladoras e a legislação ambiental das atividades de petróleo.

A escolha dos EUA se explica por ser a maior potência mundial e apresentar vasta estrutura da indústria de petróleo e gás, iniciada no século XIX. Sendo um dos pioneiros na extração de petróleo, tem ampla experiência na regulação de atividades que os envolvem. Ademais, alguns aspectos da sua legislação ambiental foram usados como alicerce para a criação da regulação relativa à E\&P (exploração e produção) de petróleo no Brasil.

\section{METODOLOGIA}

A pesquisa foi realizada a partir de um levantamento bibliográfico de livros, websites e documentos eletrônicos de fontes confiáveis. Analisa a legislação ambiental referente à indústria de petróleo de dois grandes produtores: Brasil e EUA.

\section{ENTIDADES CONTROLADORAS NA INDÚSTRIA DE PETRÓLEO}

\subsection{No Brasil}

Segundo a Constituição da República do Brasil, existem três órgãos federais que atuam na indústria de petróleo nacional: Agência Nacional do Petróleo, Gás e Biocombustíveis, Instituto Brasileiro do Meio Ambiente e Marinha do Brasil.

A ANP, autarquia federal vinculada ao MME (Ministério de Minas e Energia), foi criada em 1998 e é responsável pela contratação, regulação e fiscalização de atividades na indústria de petróleo, gás e biocombustíveis no Brasil. Possui uma secretaria executiva e 16 superintendências, que atuam em todos os segmentos da indústria, entre eles: E\&P de petróleo; refino, processamento, transporte, armazenamento e comercialização; importação e exportação; participações governamentais e royalties; distribuição e revenda; fiscalização (ANP, 201?).
O Ibama foi criado em 1989 pela lei $\mathrm{n}^{\mathrm{o}} 7.735 / 89$, a partir de uma fusão de quatro órgãos governamentais. Detém o poder de polícia ambiental, realizando o controle da qualidade do ambiente, a aprovação de uso dos recursos naturais, o licenciamento ambiental e a fiscalização, monitoramento e controle ambiental.

A Marinha do Brasil, responsável pela defesa das águas marítimas e fluviais do país desde o século XVIII, tem o papel geral de controlar e monitorar o litoral do país, protegendo-o e conhecendo mais a fundo o meio ambiente marítimo. Deve lidar imediatamente com urgências ou crises no território marítimo nacional (MD, 2017).

\subsection{Nos EUA}

Os Departamentos Executivos dos Estados Unidos são análogos aos Ministérios. Representam as unidades primárias do poder executivo do governo federal.

O DOE (Departamento de Energia) executa as responsabilidades regulatórias do gás natural, assegura o desenvolvimento responsável dos recursos de petróleo e gás americanos e mantém reservas de petróleo de emergência (DOE, 201?).

O DOI (Departamento do Interior) é o gerente e administrador dos recursos naturais americanos. Possui 9 escritórios, dos quais 4 são relevantes para a indústria de petróleo (DOI, 201?):

BLM (Escritório de Gestão de Terras): Regula a E\&P de petróleo em propriedades federais onshore $\mathrm{e}$ administra terras públicas com foco na conservação e proteção dos recursos naturais. A maior prioridade do seu programa de óleo e gás é assegurar que as operações sejam feitas com responsabilidade e segurança;

BIA (Escritório de Assuntos Indígenas): Junto ao $\mathrm{BLM}$, regula a produção de petróleo em terras indígenas;

BOEM (Escritório de Gerenciamento de Energia dos Oceanos): Lida com E\&P de recursos offshore de forma econômica e ambientalmente responsável e vende concessões de óleo e gás na OCS (plataforma continental externa)

BSSE (Escritório de Supervisão da Segurança e do meio ambiente): Responsável por melhorar a segurança e assegurar a proteção ambiental relativa ao setor de energia offshore, predominantemente óleo e gás, na OCS. Regula a preparação para emergências, a segurança dos trabalhadores, a responsabilidade ambiental e a conservação de recursos offshore. Articula e implementa regulações claras, concentrando-se na prevenção de violações. Tem autoridade para solicitar o fechamento de plataformas, poços, equipamentos ou dutos, de modo a garantir a proteção do meio ambiente e a segurança dos funcionários (BSEE, 201?).

A USCG (Guarda Costeira dos EUA), pertencente ao DHS (Departamento de Segurança Interna), tem o dever de proteger pessoas, o meio ambiente e interesses de segurança e econômicos em qualquer região da OCS. Principal agência de resposta a derrames na OCS, assegura 
que os responsáveis compensem possíveis prejuízos do país.

O ONRR (Escritório da Receita dos Recursos Naturais) desempenha um papel fiduciário, gerenciando e garantindo o pagamento integral das receitas pelo desenvolvimento de energia e dos recursos naturais, tanto onshore como offshore. Anualmente, recebe em média mais de US\$ 10 bilhões de receita não tributária. Atua em conjunto com os escritórios do DOI, apoiando a gestão de óleo, gás e outros recursos naturais (ONRR, 2018).

A EPA (Agência de Proteção Ambiental) desenvolve e coloca em prática regulamentos, com objetivo de proteger a saúde humana e o meio ambiente. Esses regulamentos são, na verdade, leis ambientais reescritas, de modo a facilitar a compreensão dos requisitos. Cerca de metade do seu orçamento é destinado a programas ambientais, estaduais, ONG's e governos estaduais e locais. É a principal agência federal de resposta a derramamentos de óleo em águas interiores. Seu programa de prevenção de derrames de óleo inclui as regras FRP (plano de resposta da instalação) e SPCC (prevenção, controle e contramedida de derrames). A regra FRP exige que instalações que armazenam ou usam óleo tenham um plano de resposta, estando preparadas para agir num grande derramamento. A regra SPCC auxilia as instalações a evitar a descarga de óleo em águas navegáveis e no litoral (EPA, 2018).

\section{LEGISLAÇÃO AMBIENTAL}

O ser humano é o maior responsável pela degradação ambiental do nosso planeta. Por essa razão se torna necessária a consolidação de metas, normas, penalidades e instrumentos.

O poder do Estado é exercido a partir da criação de instituições públicas e leis. A regulamentação é o instrumento burocrático do Estado.

\subsection{No Brasil}

Em 1953 foi instituído o monopólio estatal da E\&P de petróleo, a partir da lei $\mathrm{n}^{\circ} 2.004$, que criou a Petrobras, dispôs sobre a Política Nacional de Petróleo e definiu as atribuições do Conselho Nacional de Petróleo.

Em 1981, a partir da lei nº 6.938, a PNMA (Política Nacional do Meio Ambiente) foi sancionada, sendo o alicerce da legislação ambiental brasileira, contendo inclusive definições básicas relacionadas ao meio ambiente e à poluição. Seu objetivo geral é preservar, melhorar e recuperar a qualidade ambiental favorável à vida, garantindo o desenvolvimento socioeconômico, a proteção da vida humana e os interesses de segurança nacional. Essa lei também estruturou o SISNAMA (Sistema Nacional do Meio Ambiente) e o CONAMA (Conselho Nacional do Meio Ambiente) (BRASIL, 1981).

Iniciou-se a integração de políticas ambientais, apresentando como referência instrumentos e diretrizes especificados na referida lei, tornando-as mais eficientes. Entre esses instrumentos, destacam-se as normas associadas aos níveis permitidos de poluição, avaliação de impactos ambientais, licenciamento de atividades poluidoras, criações de áreas de proteção ambiental e penalidades para o não cumprimento das normas.
A lei $9.478 / 97$ dispôs sobre a política energética nacional, as atividades relativas ao monopólio de petróleo e instituiu o CNPE (Conselho Nacional de Política Energética) e a ANP. Determina que o óleo e gás extraído fosse de propriedade do concessionário, restringindo o monopólio da União.

Em 1998, a partir Lei dos Crimes Ambientais, definiu-se responsabilidades da pessoa jurídica, possibilitando também a incriminar a pessoa física. Os crimes ambientais são: contra a flora e a fauna, poluição, contra a administração ambiental e contra o ordenamento urbano e o patrimônio cultural. As penalidades são aplicadas de acordo com a magnitude da infração.

A lei 9.966/00, que dispõe sobre a prevenção, controle e fiscalização da poluição causada por derramamento de óleo e outras substâncias nocivas ou perigosas em águas sob jurisdição nacional, atribui aos órgãos que fiscalizem navios, plataformas e suas instalações de apoio, comunicando entre eles irregularidades encontradas durante a fiscalização e podendo autuar os infratores na sua esfera de competência. A autoridade marítima e o órgão regulador levantam dados sobre incidentes nessas instalações, encaminhando-os para o Ibama. Este, por sua vez, realiza o controle ambiental e avalia os danos ambientais causados por incidentes, encaminhando-os à Procuradoria-Geral da República (BRASIL, 2000).

\subsection{Nos EUA}

A indústria americana é regulada por meio de leis federais e estaduais. O regime jurídico depende da localização das jazidas, ou seja, se a área é federal, estadual ou privada, como também se estão em áreas onshore ou offshore.

Áreas federais onshore são regidas pelas leis MLA (lei da concessão mineral) de 1920 e 1947, que controlam a concessão de terras públicas para a exploração de combustíveis fósseis e outros, permitindo ao governo indenizar o operador por extrair minerais lá presentes. São três os tipos de pagamentos: bônus (remuneração inicial), aluguel (US\$ 2 por acre anualmente) e royalty (12,5\% do valor bruto de petróleo produzido).

O país começou a regulamentar a atividade de extração de minérios offshore no final da década de 40, mas sua jurisdição só foi estabelecida em 1953, com a OCSLA (lei de terras da plataforma continental exterior), que definiu a OCS, permitindo concessões dessas áreas (BOEM, 201?).

Em 1970 o congresso incluiu poluição por petróleo na FWPA (lei federal de poluição por água), especificando penalidades, que ainda não eram suficientes (MORGAN, 2011). Nesse mesmo ano foi assinada a NEPA (lei da política ambiental nacional), que estabelece políticas ambientais e assegura que os órgãos do governo considerem o meio ambiente antes de qualquer ação. Os requisitos mais importantes são as avaliações ambientais e as declarações de impactos ambientais (EPA, 2018).

Em 1970 a CWA (lei da água limpa) foi aprovada, iniciando-se a regulação de descargas de poluentes nas águas e padrões de qualidade para as mesmas. Ela autoriza o presidente a direcionar todas as ações cabíveis para 
responder a descargas de petróleo ou sua ameaça (EPA, 2018).

A OPA de 1990 (lei da poluição por petróleo) impôs que o óleo derramado fosse removido, elaborou processos para medir danos, obrigou as instalações a submeterem planos de resposta a grandes derrames, entre outros (EPA, 2018). A lei afetou profundamente a indústria offshore, com rigorosas determinações para suas instalações. Foi imposto o certificado de responsabilidade financeira, onde os proprietários de embarcações com mais de 300 toneladas brutas precisam provar ter condições financeiras suficientes para arcar com os custos totais de um acidente (NICHOLS, 2010).

\section{CONCLUSÕES}

Nas décadas de 60 e 70, inicialmente na Europa Ocidental e na América do Norte, ocorreu o simultâneo desenvolvimento da atividade de petróleo e da mudança na visão global do meio ambiente. Consequentemente, diversos países participaram de conferências, com o objetivo de abordar melhor os problemas ambientais através de tratados internacionais, como a conferência de Estocolmo, em 1972. Nesse princípio eram escassos os instrumentos legais que tinham como tema o meio ambiente. Esses países passaram a desempenhar um papel central na E\&P de petróleo, criando normas, regulações ambientais e requisitos específicos, e garantindo que essas atividades fossem controladas em concordância com as melhores práticas da indústria internacional, visando preservação ambiental e segurança operacional.

Através da NEPA em 1970 nos EUA, iniciou-se a proteção integral do meio ambiente, com garantias de implementação e autonomia valorativa. Inspirado na NEPA, o princípio efetivo do direito ambiental brasileiro foi tardio, com a lei da PNMA de 1981, que criou uma rede de instituições governamentais, nas três esferas do poder (ANTUNES, 2000). Apesar da influência, o direito ambiental brasileiro é de raízes mais antigas.

De certa forma, a organização institucional é similar, porém nos EUA é mais ramificada, onde cada instituição lida com um assunto específico, de forma a evitar interesses conflitantes. No Brasil existem apenas três órgãos, a autoridade marítima, a autoridade ambiental e a agência reguladora. A ANP é responsável por fiscalizar todas as atividades da indústria de petróleo, enquanto nos EUA essa fiscalização é feita por vários departamentos, como o DOE, DOI e ONRR, onde cada um exerce uma função. No presente, as entidades reguladoras de ambos os países utilizam uma gestão de segurança operacional contemporânea, onde o operador da concessão é responsável pelas suas práticas, visando deixar menor possível o grau de risco de suas operações.

Quanto à estrutura legal, os dois países apresentam leis gerais, como a PNMA e a NEPA, e leis específicas, como a Lei do Petróleo e a CWA. A diferença entre as duas constituições é que no Brasil, a constituição de caráter welfarista reconhece coletividades e instituições, enquanto nos EUA as obrigações e os direitos atuam unicamente entre o Estado e indivíduos.

\section{R E F E R E N C E S}

ANP. Agência Nacional do Petróleo, Gás Natural e Biocombustíveis. Institucional. Rio de Janeiro, 201 ? Disponível

em: <http://www.anp.gov.br/institucional>. Acesso em: 07 de julho de 2018.

ANTUNES, P. B. Direito Ambiental. 4a ed., Rio de Janeiro: Lumen Juris, 2000.

BOEM. Bureau of Ocean Energy Management. OCS Lands Act History. Washington, 201?. Disponível em: <https://www.boem.gov/ocs-lands-act-history/>. Acesso em: 10 de julho de 2018.

BRASIL. Lei $n^{\circ}$ 6.938, de 31 de agosto de 1981. Dispõe sobre a Política Nacional do Meio Ambiente, seus fins e mecanismos de formulação e aplicação, e dá outras providências. Diário Oficial da República Federativa do Brasil. Brasília/DF, 1981.

BRASIL. Lei n ${ }^{\circ}$ 9.966, de 28 de abril de 2000. Dispõe sobre a prevenção, o controle e a fiscalização da poluição causada por lançamento de óleo e outras substâncias nocivas ou perigosas em águas sob jurisdição nacional e dá outras providências. Diário Oficial da República Federativa do Brasil. Brasília/DF, 2000.

BSEE - Bureau of Safety and Environmental Enforcement. Enforcement Tools. Washington, 201?. Disponível em: <https://www.bsee.gov/what-we-do/safetyenforcement/enforcement-tools $>$. Acesso em: 09 de julho de 2018.

DOE - Department of Energy. Fossil. Washington, 201?. Disponível em: <https://energy.gov/scienceinnovation/energy-sources/fossil >. Acesso em: $08 \mathrm{de}$ julho de 2018.

DOI - Department of Interior. American Energy. Washington, 201?. Disponível em: <https://www.doi.gov/energy>. Acesso em: 08 de julho de 2018.

EPA - Environmental Protection Agency. Clean Water Act (CWA) and Federal Facilities. Washington, 2018. Disponível em: $<$ https://www.epa.gov/enforcement/clean-water-actcwa-and-federal-facilities>. Acesso em: 10 de julho de 2018.

EPA - Environmental Protection Agency. Oil spills prevention and preparedness regulations. Washington, 2018. Disponível em: $<$ https://www.epa.gov/oil-spills-prevention-andpreparedness-regulations $>$. Acesso em: 09 de julho de 2018.

EPA - Environmental Protection Agency. Summary of the National Environmental Policy Act. Washington, 2018. Disponível em: <https://www.epa.gov/lawsregulations/summary-national-environmental-policyact>. Acesso em: 18 de outubro de 2018.

EPA - Environmental Protection Agency. Summary of the Oil Pollution Act. Washington, 2018. Disponível em: <https://www.epa.gov/laws- 
regulations/summary-oil-pollution-act>. Acesso em: 18 de outubro de 2018.

GAO, Z. Environmental Regulation of Oil and Gas. $1^{\mathrm{a}}$ ed., Londres: Editora Kluwer Law International Ltd, 1998.

MD - Ministério da Defesa. Marinha do Brasil. Brasil, 2017

Disponível

em:

$<$ http://www.defesa.gov.br/index.php/forcasarmadas/marinha-do-brasil>. Acesso em: 07 de julho de 2018 .

MORGAN, J. D. The Oil Pollution Act of 1990: a look at its impact on the oil industry. Fordham Environmental Law Journal, Califórnia, v.6, n.1, art.5, 1994.

NICHOLS, J. E. Oil Pollution Act of 1990 (OPA): Liability of Responsible Parties. Estados Unidos: CRS, 2010. Disponível

em: <https://digital.library.unt.edu/ark:/67531/metadc491 360/m1/1/high_res_d/R41266_2010Jun02.pdf>. Acesso em: 18 de outubro, 2018.

ONRR - Office of Natural Resources Revenue. About ONRR. Washington, 2018. Disponível em: $<$ https://www.onrr.gov/About/>. Acesso em: $09 \mathrm{de}$ julho de 2018. 